\title{
Metode Pieces Framework Pada Tingkat Kepuasan Pengguna Sistem Informasi Perpustakaan Universitas Muhammadiyah Sorong
}

\author{
Muzakkir Pangri 1,* , Sunardi Sunardi ${ }^{2}$, Rusydi Umar ${ }^{3}$ \\ ${ }^{1}$ Magister Teknik Informatika; Universitas Ahmad Dahlan; Jalan Prof. Dr. Soepomo, Janturan, \\ Yogyakarta, 55164; e-mail: muzakkir1808048036@webmail.uad.ac.id \\ 2 Teknik Elektro; Universitas Ahmad Dahlan; Jalan Ring Road Selatan, Tamanan Banguntapan \\ Bantul, Yogyakarta, 55166; e-mail: sunardi@mti.uad.ac.id \\ 3 Teknik Informatika; Universitas Ahmad Dahlan; Jalan Ring Road Selatan, Tamanan \\ Banguntapan Bantul, Yogyakarta, 55166; e-mail: rusydi umar@rocketmail.com \\ * Korespondensi: e-mail: muzakkir1808048036@webmail.uad.ac.id
}

Diterima: 27 Mei 2021; Review: 14 Juni 2021; Disetujui: 22 Juni 2021

Cara sitasi: Pangri M, Sunardi S, Umar R. 2021. Metode Pieces Frameworks Pada Tingkat Kepuasan Pengguna Sistem Informasi Perpustakaan Universitas Muhammadiyah Sorong. Bina Insani ICT Journal. Vol. 8 (1): 63-72.

\begin{abstract}
Abstrak: Sistem informasi mempunyai peran penting dalam menghasilkan informasi bagi semua tingkatan manajemen. Analis perlu mengetahui keperluan informasi yang diinginkan manajemen agar informasi yang dihasilkan oleh sistem informasi dapat berfungsi dan tepat bagi manajemen. Proses evaluasi terhadap kinerja dari sistem informasi diperlukan untuk mengetahui apakah sistem informasi Universitas Muhammadiyah Sorong berjalan sebagaimana mestinya. Evaluasi sistem informasi dapat dilakukan dengan cara yang berbeda dan pada tingkatan yang berbeda, tergantung pada tujuan evaluasinya. Dalam melakukan kegiatan analisis dan evaluasi sistem informasi, terdapat beberapa metode atau model analisis yang dapat digunakan salah satunya adalah model analisis PIECES Framework. Untuk mempermudah evaluasi, ditawarkan cara analisis dengan kerangka PIECES Framework yang menguraikan ke dalam 6 fokus analisis kelemahan yaitu Performance, Information and Data, Economy, Control and Security, Eficiency dan Service. Tujuan penelitan ini untuk mengukur tingkat kepuasan, mengetahui kelemahan serta kekuatan dan menganalisis komponenkomponen yang diperlukan untuk meningkatkan kualitas pelayanan, yang terdapat pada sistem informasi perpustakaan Universitas Muhammadiyah Sorong. Berdasarkan hasil perhitungan daftar pernyataan yang diberikan kepada responden yang merupakan pengguna sistem informasi perpustakaan Universitas Muhammadiyah Sorong, domain Performance, Information \& Data, Economics, Control \& Security, Efficiency, dan Service, semua berada pada kategori puas, artinya penerapan sistem informasi perpustakaan Universitas Muhammadiyah Sorong, yang saat ini digunakan dilingkungan Kampus sudah dapat diterima sesuai dengan kerangka PIECES Framework.
\end{abstract}

Kata kunci: kepuasan pengguna, PIECES Framework, website.

Abstract: Information systems have an important role in producing information for all levels of management. Analysts need to know necessity of the information that management wants so that the information generated by the information system can function and be appropriate for management. The process of evaluating performance of the information system is needed to determine whether the information system at the University of Muhammadiyah Sorong is running as it should. Information systems evaluation can be carried out in different ways and at 
different levels, depending on objective of the evaluation. In carrying out information system analysis and evaluation activities, there are several methods or analysis models that can be used, one of which is the PIECES Framework analysis model. To simplify the evaluation, an analysis method is offered with the PIECES Framework which describes the 6 focus of weakness analysis, that are Performance, Information and Data, Economy, Control and Security, Efficiency and Service. The purpose of this research is to measure the level of satisfaction, find out the strengths, weaknesses and analyze the components that need to be improved the quality of service, which is contained in the library information system of the Muhammadiyah University of Sorong. Based on the results of the calculation of the list of statements given to respondents who are users of the library information system at the Muhammadiyah University of Sorong, the domain of Performance, Information \& Data, Economics, Control \& Security, Efficiency and Service, all of in the satisfied category, meaning that the application of the library information system at the Muhammadiyah University of Sorong , which is currently being used in the campus environment is acceptable in accordance with the PIECES Framework.

Keywords: user satisfaction, PIECES Framework, website.

\section{Pendahuluan}

Sistem informasi berbasis website adalah representasi dari teknologi informasi yang merupakan media dalam memperoleh informasi. Salah satu manfaat dari sistem informasi berbasis website adalah mempermudah penyajian data yang dapat diakses oleh semua pengguna internet [1]. Peranan dari sistem informasi berbasis website yaitu dapat menghasilkan informasi untuk semua tingkat manajemen. Keperluan akan informasi bagi suatu manajemen harus dilakukan proses analisa, sehingga informasi yang dihasilkan dapat berfungsi dan tepat sasaran [2]. Salah satu penerapan sistem informasi berbasis website adalah sistem informasi perpustakan.

Kemudahan dalam mewujudkan tridharma Perguruan Tinggi di sebuah institusi Pendidikan Tinggi tidak lepas dari peranan perpustakaan yang tertera pada Standar Nasional Perpustakaan Perguruan Tinggi [3]. Pada saat sekarang ini perpustakaan telah berkembang sesuai dengan perkembangan teknologi yaitu dengan adanya perpustakaan berbasis website. Sistem informasi perpustakan berbasis website adalah implementasi dari teknologi informasi dalam proses manajemen perpustakaan. Proses integrasi yang diimplemeentasikan dalam sistem informasi perpustakaan yaitu pengelolaan anggota, inventarisasi, statistik, dan lain sebagainya. Proses integrasi tersebut dapat disebut sebagai bentuk Automatisasi Perpustakaan [4]. Dengan adanya sistem informasi perpustakaan diharapkan mampu mempermudah proses manajemen perpustakaan sehingga dapat memberikan manfaat sesuai dengan apa yang diinginkan.

Universitas Muhammadiyah Sorong merupakan salah satu universitas terbesar yang ada di Provinsi Papua Barat. Dalam proses mewujudkan tridharma Perguruan Tinggi, Universitas Muhammadiyah Sorong memanfaatkan sistem informasi perpustakaan berbasis website untuk memudahkan manajemen perpustakan yang ada di Univeritas tersebut. Dalam proses mengoprasikan sistem informasi perpustakaan diperlukan 3 komponen utama, yaitu hardware, software, dan brainware (user). Ketiga komponen tersebut harus saling terintegrasi agar sistem informasi tersebut dapat berjalan dengan baik. Untuk mengetahui tingkat keberhasilan dalam proses implementasi sistem informasi perpustakaan perlu adanya evaluasi sistem.

Penelitian ini dilakukan proses evaluasi terhadap sistem informasi perpustakaan yang ada di Universitas Muhammadiyah Sorong. Proses evaluasi yang dilakukan bertujuan untuk memberikan gambaran dari permasalahan yang terjadi dalam pengoperasian sistem informasi tersebut dengan menggunakan instrumen sesuai metode yang digunakan dan kemudian hasilnya dianalisa sehingga memperoleh kesimpulan yang dapat dijadikan solusi dalam menyelesaikan permasalahan yang muncul. Tujuan dari proses evaluasi sistem informasi yaitu untuk memberikan penilaian pendayagunaan sistem, kemampuan teknis dan pelaksanaan operasional [5].

Hasil dari observasi yang dilakukan ditemukan bahwa sistem informasi perpustakaan Universitas Muhammadiyah Sorong belum pernah di evaluasi sebelumnya sehingga belum diketahui tingkat keberhasilan dari sistem tersebut. Keberhasilan dari sistem informasi dapat 
ditinjau berdasarkan faktor kepuasan serta persepsi penggunanya. Dengan demikian, diperlukan adanya pengujian sistem informasi perpustakaan sehingga dapat diketahui tingkat keberhasilan atau kegagalan dalam proses implementasi sistem informasi dengan pengukuran berdasarkan indikator kepuasan pengguna. Proses evaluasi dilakukan menggunakan metode PIECES Fremwork. Metode PIECES Fremwork meliputi evaluasi kelayakan sistem untuk di jadikan sebagai software otomasi perpustakaan dari segi Performance (Keandalan), Information and Data (Data dan Informasi), Economics (Nilai Ekonomis), Control and Security (Pengendalian dan Pengamanan), Efficiency (Efisiensi) kemudahan dalam mencapai kepuasan pengguna akhir.

\section{Metode Penelitian}

Tahapan pertama dalam penelitian ini yaitu dimulai dengan observasi terhadap sistem informasi perpustakaan yang ada pada Universitas Muhammadiyah Sorong, serta melakukan proses wawancara kepada pihak pengelola dan yang berperan dalam sistem tersebut [7] [8]. Tahapan pertama ini bertujuan untuk menentukan permasalahan objek penelitian. Kemudian tahapan yang kedua yaitu melakukan studi literatur serta melakukan proses review terhadap penelitian sebelumnya sehingga penelitian yang dilakukan memiliki dasar yang jelas. Tahapan selanjutnya yaitu melakukan proses pencarian data. Data yang digunakan dalam penelitian ini merupakan data primer yang diperoleh dengan menyebarkan kuisioner dalam bentuk google form kepada responden. Responden tersebut merupakan pengguna dari sistem informasi perpustakaan yang ada pada Universitas Muhammadiyah Sorong atau dalam hal ini yaitu mahasiswa dengan populasi yang berjumlah 5.139 orang. Berdasarkan jumlah populasi tersebut kemudian ditentukan sampel sebanyak 104 mahasiswa, penentuan sampel dilakukan dengan menggunakan rumus Taro Yamane [9] berikut ini:

$$
n=\frac{N}{N \cdot d^{2}+1}
$$

Keterangan:

$\mathrm{n} \quad$ = jumlah sampel seluruhnya

$\mathrm{N}=$ jumlah populasi

d $\quad=$ tingkat presisi $(10 \%)$

Tahap berikutnya yaitu proses pembuatan kuisioner yang disesuaikan dengan metode yang digunakan yaitu metode PIECES Framework. Metode PIECES framework merupakan suatu kerangka yang digunakan untuk proses klasifikasi suatu permasalahan (problem), peluang (opportunities), serta arahan (directives) yang ada pada scope definition analysis dan perancangan sistem. PIECES framework dapat menghasilkan hal baru untuk dijadikan bahan pertimbangan pada proses pengembangan sistem. Metode PIECES framework memilki enam komponen utama yang dapat digunakan dalam proses evaluasi kepuasan pengguna sistem informasi [11], yaitu: 1) Kehandalan (Performance), variable performance berperan penting dalam proses pengamatan terhadap kehandalan sistem informasi pada proses pengolahan data untuk menghasilkan informasi dan mencapai tujuan yang diharapkan. Dalam proses evaluasi kenirja suatu sistem, terdapat dua komponen utama sebagai acuan yang harus diperhatikan, yaitu: a) Apakah suatu sistem dapat atau mampu mengerjakan sejumlah perintah dalam periode waktu yang telah ditentukan dengan baik dan tanpa hambatan, b) Sejauh mana kemampuan sebuah sistem dalam merespon suatu perintah maupun permintaan terhadap suatu transaksi apakah cepat atau lambat; 2) Informasi dan Data (Data and Information), salah satu faktor penting untuk kemajuan suatu perusahan yaitu kebutuhan dalam penyajian data dan informasi. Hasil dari sistem informasi berupa data dan informasi harus memiliki nilai sehingga dapat dipergunakan dalam proses pengambilan keputusan oleh manajemen perusahaan. Adapun komponen yang perlu diperhatikan dalam proses evaluasi sistem yang berkaitan dengan data dan informasi yaitu: a) Keluaran (Output), merupakan hasil yang diperoleh dari sistem serta penyajian informasi yang dibutuhkan oleh perusahaan, b) Masukan (Input), merupakan kinerja sistem dalam memasukkan data dan kemudian mengolah data tersebut menjadi informasi yang berguna untuk perusahaan, c) Data yang disimpan (Stored Data), merupakan tingkat kehandalan sistem dalam proses penyimpanan data serta proses 
pengaksesan data tersebut; 3) Nilai Ekonomis (Economics), variable economics merupakan parameter terhadap pengorbanan perusahaan dalam mengimplementasikan suatu sistem informasi dengan hasil yang diperoleh. Proses evaluasi sistem dari segi ekonomi memiliki dua komponen yang perlu diperhatikan, yaitu: a) Biaya, merupakan evaluasi terhadap biaya yang digunakan perusahaan dalam penerapan sistem informasi, b) Keuntungan, merupakan evaluasi terhadap keuntungan yang diperoleh perusahaan dalam penerapan sistem informasi sehingga perusahan dapat menjadi lebih baik; 4) Pengamanan dan Pengendalian (Control and Security), variable control and security merupakan proses pengamanan dan pengendalian sistem sehingga sistem tersebut terhindar dari gangguan yang tidak diinginkan. Hal yang perlu diperhatikan dalam pengendalian dan pengamanan suatu sistem informasi yaitu: a) Pengamanan dan pengendalian terhadap sistem terlalu lemah, b) Pengamanan dan pengendalian terhadap sistem terlalu tinggi atau kompleks; 5. Efisiensi (Efficiency), penggunaan sistem informasi harus secara mutlak unggul dengan sistem manual. Keunggulan tersebut terdapat pada tingkat efisiensi saat proses pengoperasian sistem infromasi. Acuan yang perlu diperhatikan pada proses analisa dan evaluasi sistem informasi berdasarkan segi efisiensi yaitu: a) Penggunaan karyawan, mesin atau computer memerlukan waktu yang banyak atau pemborosan dalam penggunaan persediaan dan material perusahaan, b) Pemenuhan tugas ataupun pekerjaan, ditinjau dari usaha yang diperlukan dalam menjalankan kegiatan menjadi berlebihan, c) Pemenuhan kebutuhan material secara berlebihan hanya untuk menyelesaikan suatu tugas tertentu; 6) Pelayanan (Service), pelayanan konsumen merupakan salah satu aspek penting yang perlu diperhatikan, konsumen yang dimakud dalam hal ini yaitu pengguna sistem informasi. Pengguna sistem informasi harus diberikan pelayanan yang baik sehingga pengguna tersebut dapat merasa puas dan tertarik serta tidak beralih ke pesaing bisnis lainnya. Hal yang perlu diperhatikan dan dinilai penting dalam proses mempertahankan konsumen yaitu: a) Sistem harus dapat menghasilkan informasi yang akurat serta sesuai dengan kebutuhan pengguna, b) Hasil yang diperoleh dari sebuah sistem haruslah konsisten, c) Penerapan sistem harus mudah dipelajari, dimengerti serta mudah digunakan oleh pengguna, sehingga pengguna akan merasa nyaman pada saat menggunakan sistem informasi tersebut, d) Sistem harus bersifat fleksibel dan kompatibel. Variabel penelitian dengan: 1) Dimensi Performance (Kehandalan) dengan definisi seberapa cepat suatu data dapat ditemukan dan indikator: mudah mengakses, proses dilakukan dengan cepat, stabil, dan pengolahan data cepat; 2) Dimensi Information and Data (Data dan Informasi) dengan definisi seberapa banyak dan seberapa jelas informasi yang akan dihasilkan untuk satu pencarian dan indikator: data tersimpan sesuai, informasi sesuai, informasi bermanfaat digunakan, dan informasi mudah dipelajari; 3) Dimensi Economics (Nilai Ekonomis) dengan definisi mengetahui apakah suatu sistem itu tepat diterapkan pada suatu lembaga informasi dilihat dari segi finansial dan biaya yang dikeluarkan dan indikator: perubahan Signifikan lebih baik, menjaga data informasi; 4) Dimensi Control and Security (Pengendalian dan Pengamanan) dengan definisi mengetahui sejauh mana pengawasan dan kontrol yang dilakukan agar sistem tersebut berjalan dengan baik dan indikator: pengontrolan pihak pengelola, pengamanan, dan meringankan pengguna; 5) Dimensi Efficiency (Efisiensi) dengan definisi mengetahui apakah suatu sistem itu efisien atau tidak, dengan input yang sedikit bisa menghasilkan sebuah output yang memuaskan dan indikator: memajukan dan mempermudah; 6) Dimensi Service (Pelayanan) dengan definisi mengetahui bagaimana pelayanan yang dilakukan dan mengetahui permasalahan -permasalahan yang ada terkait tentang pelayanan dan indikator: sistem mudah dipelajari, sistem teritegrasi dan sistem memberi kepuasan.

\section{Pengumpulan Data}

Instrumen dalam penelitian ini adalah menggunakan metode kuisioner yang bersifat tertutup (close-ended question) sehingga hasil yang dicapai dari metode kuisioner ini dapat kompleks dan akurat. Ada beberapa pernyataan atau pertanyaan tertulis yang digunakan untuk memperoleh informasi dari responden tentang tingkat kepuasan pengguna Sistem Informasi Perpustakaan UMSorong, Kuisioner ini terdiri beberapa pernyataan yang akan menjadi variabel dalam penelitian. Variabel tersebut yaitu Performance (Keandalan), Information and Data (Data dan Informasi), Economics (Nilai Ekonomis), Control and Security (Pengendalian dan Pengamanan), Efficiency (Efisiensi), Service (Pelayanan) [12]. 


\section{Hasil dan Pembahasan} Analisis Sistem

Perpustakaan Universitas Muhammadiyah Sorong (UMSorong) dalam memberikan layanan layanan pengarsipan data buku, referensi dan mencetak label sudah menggunakan beberapa fitur sistem informasi. Fitur tersebut seperti sistem peminjaman buku, sistem katalog pencarian buku, Sistem pengembalian buku, dan lain lain. Berikut ini adalah tampilan halaman depan dari sistem informasi perpustakaan UMSorong dijelaskan pada gambar 1.

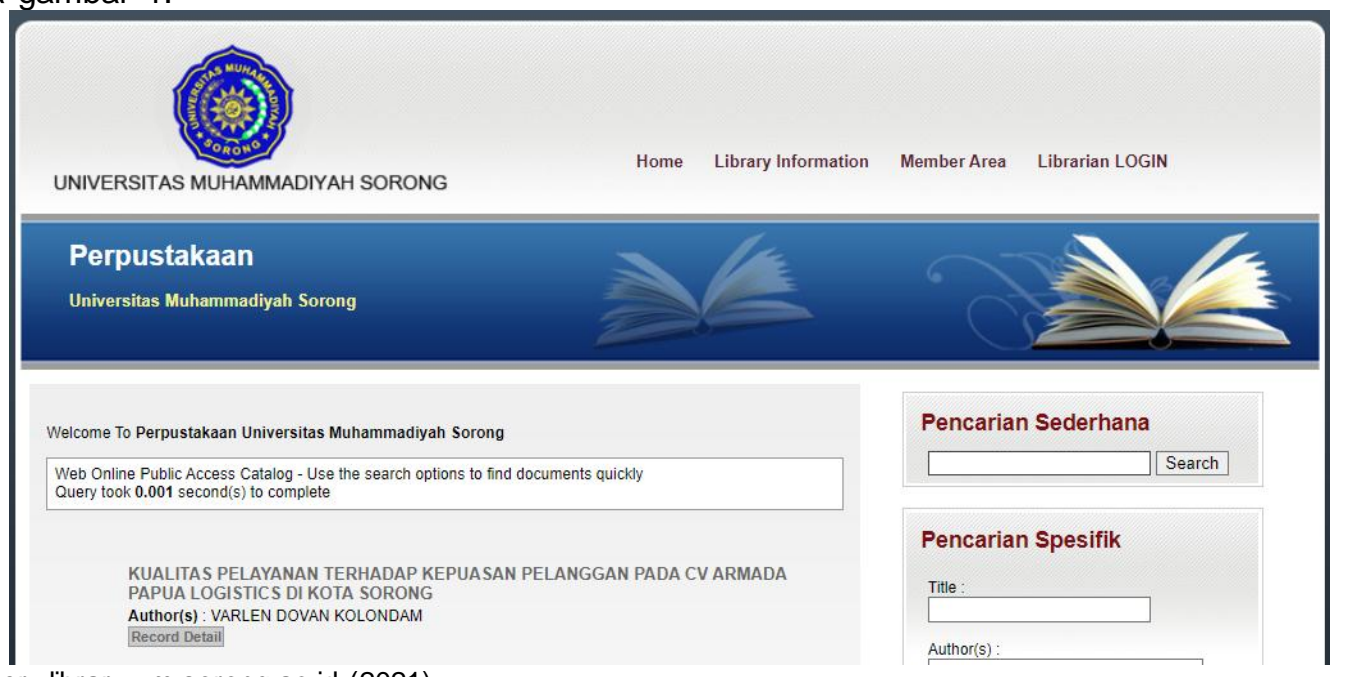

Sumber: library.um-sorong.ac.id (2021)

Gambar 1. Halaman Depan Sistem Informasi Perpustakaan

Halaman untuk login member dengan memasukkan member ID dan password pada Sistem Informasi Perpustakaan dijelaskan pada gambar 2.

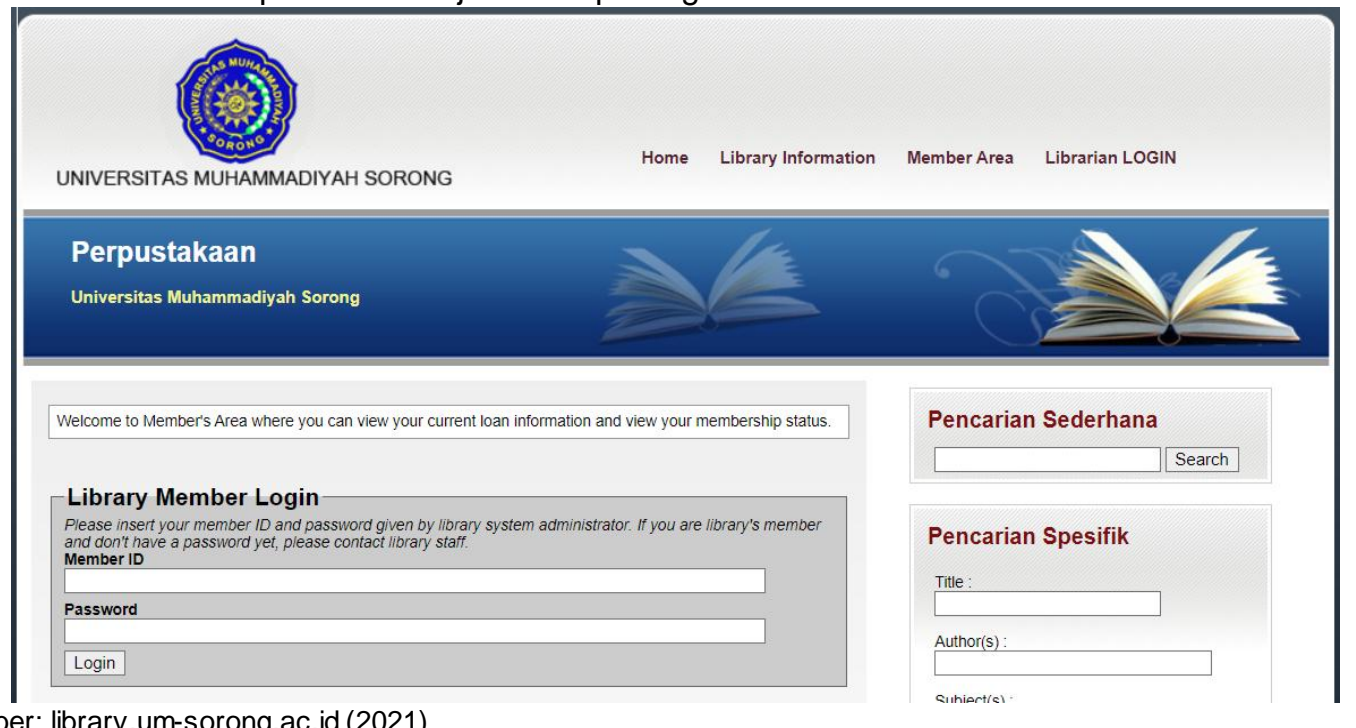

Sumber: library.um-sorong.ac.id (2021)

Gambar 2. Halaman Login Member Sistem Informasi Perpustakaan

\section{Karakteristik responden}

Responden sebanyak 104 yang mengisi kuesioner yang diberikan. Sebanyak 54,8\% responden berjenis kelamin perempuan dan dan $45,2 \%$ berjenis kelamin laki-laki. Keseluruhan Mahasiswa merupakan mahasiswa UMSorong dan sudah atau sedang menggunakan Sistem Informasi Perpustakaan UMSorong. Untuk lebih jelasnya dapat dilihat pada gambar 3. 


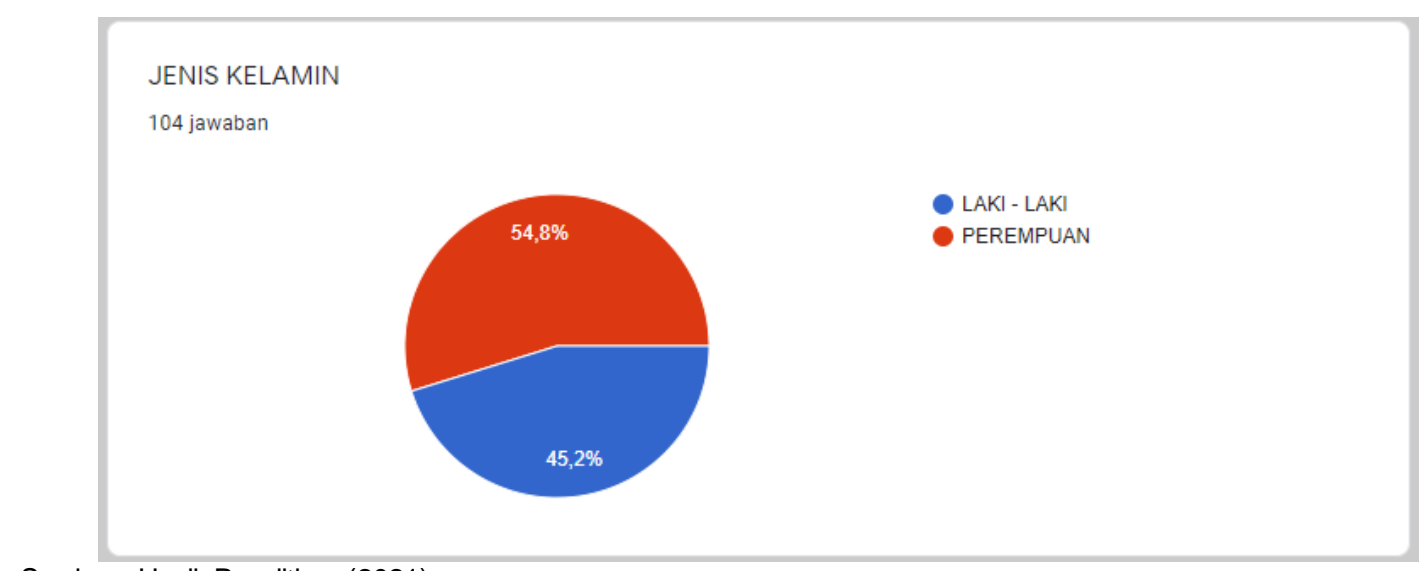

Sumber: Hasil Penelitian (2021)

Gambar 3. Diagram jenis kelamin responden

\section{Perhitungan dan Analisis Data}

Dari hasil kuesioner disebar kepada 104 mahasiswa yang menggunakan sistem informasi perpustakaan, dengan menggunakan skala Likert untuk mengetahui kepuasan pengguna sistem informasi perpustakaan sesuai dengan pilihan dan skornya, maka untuk mendapatkan hasil tingkat kepuasan dengan menggunakan rumus [13]:

$R K=\frac{J S K}{J K}$

Keterangan:

RK = Rata - Rata Kepuasan

JSK = Jumlah Skor Kuesioner

$\mathrm{JK}=$ Jumlah Kuesioner

Dimana kemudian menentukan interval kelas dan penggunaan rata-rata skala likert [12]:

Rumus Menentukan interval kelas [14]

$i=\frac{r}{k}$

Keterangan:

$\mathrm{i}=$ Interval Kelas

$r=$ Range (Skala Tertinggi - Skala Terendah)

$\mathrm{k}=$ Jumlah Kelas

Karakter penilaian dijelaskan pada skala 1-1,8 dengan kategori penilaian sangat tidak puas, skala 1,81-2,61 dengan kategori penilaian tidak puas, skala 2,62-3,42 dengan kategori penilaian ragu-ragu, skala 3,43-4,23 dengan kategori penilaian puas, dan skala 4,24-5 dengan kategori penilaian sangat puas. Dengan penentuan tingkat kepuasan seperti diatas, diperoleh rata-rata tingkat kepuasan pengguna petugas perpustakaan berdasarkan domain yang terdapat pada PIECES Framework adalah sebagai berikut:

\section{Performance}

Pada domain performance terdapat empat poin pernyataan terkait pelayanan informasi perpustakaan UMSorong, perhitungan dengan domain performance untuk pernyataan: 1) Mudah saat mengakses sistem informasi perpustakaan UMSorong, 2) Sistem informasi perpustakaan UMSorong dalam merespon suatu perintah pembatalan maupun permintaan terhadap suatu proses dapat dilakukan dengan cepat, 3) Pada saat sistem informasi perpustakaan UMSorong digunakan secara bersamaan, kinerja sistem informasi tetap berjalan stabil, dan 4) Total waktu yang dibutuhkan dalam melakukan pengolahan data hingga menghasilkan informasi dapat dilakukan dengan cepat. Jawaban responden terhadap variabel performance dijelaskan pada tabel 1 . 
Tabel 1. Jawaban Responden terhadap variabel Performance

\begin{tabular}{cccccc}
\hline Pilihan & \multicolumn{7}{c}{ Pernyataan } & \multirow{2}{*}{ Total } \\
Jaw aban & P1 & P2 & P3 & P4 & 100 \\
\hline Sangat Puas & 32 & 26 & 21 & 21 & 176 \\
\hline Puas & 45 & 40 & 44 & 47 & 119 \\
\hline Ragu-Ragu & 22 & 35 & 32 & 30 & 18 \\
\hline Tidak Puas & 4 & 3 & 6 & 5 & 3 \\
\hline Sangat Tidak Puas & 1 & 0 & 1 & 1 &
\end{tabular}

Sumber: Hasil Penelitian (2021)

$$
\begin{aligned}
& R K=\frac{(5 \times 100)+(4 \times 176)+(3 \times 119)+(2 \times 18)+(1 \times 3)}{416} \\
& R K=3,84
\end{aligned}
$$

Dari hasil perhitungan nilai rata-rata pada domain performance, didapatkan nilai 3,84 dan berdasarkan tabel penilaian berada dikategori PUAS. Maka hal ini menandakan indikasi positif bahwa performa sistem informasi perpustakaan UMSorong dapat diterima dan telah berjalan dengan baik.

\section{Information and Data}

Pada domain information and data terdapat empat poin pernyataan terkait pelayanan informasi perpustakaan UMSorong, perhitungan dengan doman information and data untuk pernyataan: 1) Data yang disimpan oleh sistem informasi perpustakaan UMSorong tersimpan sesuai dengan yang dimasukkan kedalam sistem, 2) Informasi yang dihasilkan oleh sistem informasi perpustakaan UMSorong sesuai dengan yang dibutuhkan, 3) Format informasi yang dihasilkan oleh sistem informasi perpustakaan UMSorong bermanfaat dan dapat digunakan sebagaimana mestinya oleh pengguna, dan 4) Informasi yang disajikan sistem informasi perpustakaan UMSorong mudah untuk dipelajari dan dipahami.Jawaban responden terhadap variabel variabel information and data dijelaskan pada tabel 2.

Tabel 2. Jawaban Responden terhadap variabel Information and Data

\begin{tabular}{cccccc}
\hline Pilihan & \multicolumn{2}{c}{ Pernyataan } & \multicolumn{2}{c}{ Total } \\
Jawaban & P1 & P2 & P3 & P4 & \\
\hline Sangat Puas & 22 & 29 & 24 & 23 & 98 \\
\hline Puas & 55 & 42 & 48 & 53 & 198 \\
\hline Ragu-Ragu & 23 & 28 & 29 & 25 & 105 \\
\hline Tidak Puas & 3 & 4 & 2 & 3 & 12 \\
\hline Sangat Tidak Puas & 1 & 1 & 1 & 0 & 3 \\
\hline
\end{tabular}

Sumber: Hasil Penelitian (2021)

$$
\begin{aligned}
& R K=\frac{(5 \times 98)+(4 \times 198)+(3 \times 105)+(2 \times 12)+(1 \times 3)}{416} \\
& R K=3,90
\end{aligned}
$$

Hasil perhitungan nilai rata-rata pada domain Information and Data, didapatkan nilai 3,90 dan berdasarkan tabel penilaian berada dikategori PUAS. Maka hal ini menandakan indikasi positif bahwa performa sistem informasi perpustakaan UMSorong dapat diterima dan telah berjalan dengan baik.

\section{Economics}

Pada domain economics terdapat dua poin pernyataan terkait pelayanan informasi perpustakaan UMSorong, perhitungan dengan domain economics untuk pernyatatan: 1) Ada perubahan yang signifikan dalam hal perkembangan proses akademik menjadi lebih baik dengan adanya sistem informasiperpustakaan UMSorong, 2) Sistem pengamanan yang terdapat pada sistem informasi perpustakaan UMSorong dapat menjaga data atau informasi dari berbagai bentuk kecurangan atau kejahatan. Jawaban responden terhadap variabel economics dijelaskan pada tabel 3.

Tabel 3. Jawaban Responden terhadap variabel Economics

\begin{tabular}{cccc}
\hline Pilihan & P1 & Pernyataan & Total \\
\hline Jawaban & 20 & 28 & 48 \\
\hline Sangat Puas & 50 & 42 & 92 \\
\hline Puas & &
\end{tabular}




\begin{tabular}{|c|c|c|c|}
\hline \multirow{2}{*}{$\begin{array}{c}\text { Pilihan } \\
\text { Jawaban }\end{array}$} & \multicolumn{2}{|c|}{ Pernyataan } & \multirow{2}{*}{ Total } \\
\hline & P1 & P2 & \\
\hline Ragu-Ragu & 29 & 31 & 60 \\
\hline Tidak Puas & 5 & 3 & 8 \\
\hline Sangat Tidak Puas & 0 & 0 & 0 \\
\hline
\end{tabular}

Sumber: Hasil Penelitian (2021)

$$
\begin{aligned}
& R K=\frac{(5 \times 48)+(4 \times 92)+(3 \times 60)+(2 \times 8)+(1 \times 0)}{208} \\
& R K=3,86
\end{aligned}
$$

Hasil perhitungan nilai rata-rata pada domain Economics, didapatkan nilai 3,86 dan berdasarkan tabel penilaian berada dikategori PUAS. Maka hal ini menandakan indikasi positif bahwa performa sistem informasi perpustakaan UMSorong dapat diterima dan telah berjalan dengan baik.

\section{Control and Security}

Pada domain control and security terdapat tiga poin pernyataan terkait pelayanan informasi perpustakaan UMSorong, perhitungan dengan domain control and security untuk pernyataan: 1) Terdapat pengontrolan oleh pihak pengelola yang dilakukan secara terpusat terhadap penggunaan data, 2) Sistem pengamanan pada sistem informasi perpustakaan UMSorong tergolong baik, dan 3) Sistem yang digunakan sekarang lebih meringankan pengguna baik dari segi biaya dan waktu. Jawaban responden terhadap variabel control and security, yaitu: a) Pilihan jawaban sangat puas dengan pertanyaan $\mathrm{P} 1=23, \mathrm{P} 2=24, \mathrm{P} 3=28$, dan Total=75, b) Pilihan jawaban puas dengan pertanyaan $P 1=44, P 2=52, P 3=46$, dan Total=142, c) Pilihan jawaban ragu-ragu dengan pertanyaan $\mathrm{P} 1=35, \mathrm{P} 2=25, \mathrm{P} 3=25$, dan Total $=85$, d) Pilihan jawaban tidak puas dengan pertanyaan $\mathrm{P} 1=1, \mathrm{P} 2=2, \mathrm{P} 3=4$, dan Total $=7$, dan e) Pilihan jawaban sangat tidak puas dengan pertanyaan $P 1=1, P 2=1, P 3=1$, dan Total $=3$.

$$
\begin{aligned}
& R K=\frac{(5 \times 75)+(4 \times 142)+(3 \times 85)+(2 \times 7)+(1 \times 3)}{312} \\
& R K=3,89
\end{aligned}
$$

Hasil perhitungan nilai rata-rata pada domain Control and Security, didapatkan nilai 3,89 dan berdasarkan tabel penilaian berada dikategori PUAS. Maka hal ini menandakan indikasi positif bahwa performa sistem informasi perpustakaan UMSorong dapat diterima dan telah berjalan dengan baik.

\section{Efficiency}

Pada domain efficiency terdapat dua poin pernyataan terkait pelayanan informasi perpustakaan UMSorong, perhitungan dengan domain efficiency untuk pernyataan: 1) Penggunaan sistem informasi berperan dalam hal memajukan proses akademik UMSorong, 2) Sistem dapat mempermudah proses akademik di UMSorong. Jawaban responden terhadap variabel domain efficiency, yaitu: a) Pilihan jawaban sangat puas dengan pertanyaan $P 1=30$, $\mathrm{P} 2=29$, dan Total $=59$, b) Pilihan jawaban puas dengan pertanyaan $\mathrm{P} 1=51, \mathrm{P} 2=47$, dan Total $=98$, c) Pilihan jawaban ragu-ragu dengan pertanyaan $P 1=21, P 2=27$, dan Total $=48$, d) Pilihan jawaban tidak puas dengan pertanyaan $\mathrm{P} 1=2, \mathrm{P} 2=1$, dan Total $=3$, dan e) Pilihan jawaban sangat tidak puas dengan pertanyaan $\mathrm{P} 1=0, \mathrm{P} 2=0$, dan Total $=0$.

$$
\begin{aligned}
& R K=\frac{(5 \times 59)+(4 \times 98)+(3 \times 48)+(2 \times 3)+(1 \times 0)}{208} \\
& R K=4,02
\end{aligned}
$$

Hasil perhitungan rata-rata domain Efficiency, didapat nilai 4,02 dan berdasarkan tabel penilaian berada dikategori PUAS. Maka hal ini menandakan indikasi positif bahwa performa sistem informasi perpustakaan UMSorong dapat diterima dan telah berjalan dengan baik. 


\section{Service}

Pada domain service terdapat tiga poin pernyataan terkait pelayanan informasi perpustakaan UMSorong, perhitungan dengan doman service untuk pernyataan: 1) Sistem informasi perpustakaan UMSorongmudah dipelajari dan dipahami, 2) Sistem informasi perpustakaan UMSorong terkoordinir dan terintegrasi dengan sistem yang lain, dan 3) Sistem informasi perpustakaan UMSorong dapat memberikan kepuasan anda sebagai mahasiswa dalam melakukan proses akademik Jawaban Responden terhadap variabel domain service, yaitu: a) Pilihan jawaban sangat puas dengan pertanyaan $\mathrm{P} 1=28, \mathrm{P} 2=20, \mathrm{P} 3=29$, dan Total=77, b) Pilihan jawaban puas dengan pertanyaan $\mathrm{P} 1=47, \mathrm{P} 2=49, \mathrm{P} 3=48$, dan Total=144, c) Pilihan jawaban ragu-ragu dengan pertanyaan $\mathrm{P} 1=26, \mathrm{P} 2=30, \mathrm{P} 3=24$, dan Total=80, d) Pilihan jawaban tidak puas dengan pertanyaan $P 1=2, P 2=5, P 3=3$, dan Total=10, dan e) Pilihan jawaban sangat tidak puas dengan pertanyaan $\mathrm{P} 1=1, \mathrm{P} 2=0, \mathrm{P} 3=0$, dan Total $=1$.

$$
\begin{aligned}
& R K=\frac{(5 \times 77)+(4 \times 144)+(3 \times 80)+(2 \times 10)+(1 \times 1)}{312} \\
& R K=3,91
\end{aligned}
$$

Hasil perhitungan rata-rata domain Service, didapat nilai 3,91 dan berdasarkan tabel penilaian berada dikategori PUAS. Maka hal ini menandakan indikasi positif bahwa performa sistem informasi perpustakaan UMSorong dapat diterima dan telah berjalan dengan baik dijelaskan pada tabel 4.

Tabel 4. Nilai Skor Rekap Variabel PIECES

\begin{tabular}{cccc} 
& \multicolumn{3}{c}{ Tabel 4. Nilai Skor Rekap Variabel PIECES } \\
\cline { 2 - 4 } & Domain & Rata-Rata & Kategori \\
\cline { 2 - 4 } & Performance & 3,85 & Puas \\
\hline Information and Data & 3,9 & Puas \\
\hline Economics & 3,86 & Puas \\
\hline Control and Security & 3,89 & Puas \\
\hline Efficiency & 4,02 & Puas \\
\hline Service & 3,91 & Puas \\
\hline
\end{tabular}

Sumber: Hasil Penelitian (2021)

\section{Kesimpulan}

Kesimpulan dari penelitian ini Berdasarkan hasil dari perhitungan susunan pernyataan telah diberikan pada responden yang mengunakan sistem informasi perpustakaan Universitas Muhammadiyah Sorong, dari Performance, Information \& Data, Economics, Control \& Security, Efficiency, dan Service dikategori PUAS, berarti penggunaan sistem informasi perpustakaan Universitas Muhammadiyah Sorong yang digunakan pada lingkungan Kampus berdasarkan metode PIECES Framework telah diterima pengguna dan telah berjalan baik. Meskipun telah diterima, sistem informasi perpustakaan Universitas Muhammadiyah Sorong harus ditingkatkan lagi kedepannya agar sistem yang sudah ada diharapkan pengguna menjadi lebih direspon dengan kategori SANGAT PUAS.

\section{Referensi}

[1] M. Nur, "Indonesian Treasury Review," J. Perbendaharaan, Keuang. Negara dan Kebijak. Publik, vol. 5, no. 3, pp. 217-234, 2020.

[2] R. Umar, S. Sarjimin, A. S. Nugroho, A. Dito, and I. Gunawan, "Perancangan Sistem Informasi Keuangan Berbasis Web Multi User Dengan UML," J. Algoritm., vol. 17, no. 2, pp. 204-211, 2021, doi: 10.33364/algoritma/v. 17-2.204.

[3] W. Meilita, "Pemanfaatan Website Dan Media Sosial Perpustakaan," J. IImu Informasi, Perpustakaan, dan Kearsipan Univ. Indones., vol. 22, no. April, pp. 37-47, 2020.

[4] Wardani, "Sistem Informasi Perpustakaan Berbasis Web Di Smp N 32 Semarang," Sist. Inf. Perpust. Berbas. Web Di SMP N 32 Semarang, 2017.

[5] N. Junaedi, "Analisa Kepuasan Mahasiswa Terhadap Sistem Informasi Perpustakaan Universitas Merdeka Madiun Menggunakan Framework Pieces," Res. Comput. Inf. Syst. Technol. Manag., vol. 1, no. 2, p. 59, 2018, doi: 10.25273/research.v1i02.3364.

[6] S. Kasus, D. Kabupaten, H. Sudibyo, and B. S. W. A, "Analisis Tingkat Kepuasan Pengguna Pada Penerapan Sistem Informasi Pendidikan ( Dapodikmen )," Anal. Tingkat 
Kepuasan Pengguna Pada Penerapan Sist. Inf. Pendidik. (Studi Kasus Dindikbudpora Kabupaten Purworejo), vol. 5, no. 8, pp. 57-71, 2016.

[7] S. Keputusan Dirjen Penguatan Riset dan Pengembangan Ristek Dikti, E. Sorongan, J. Teknik Elektro, P. Teknik Elektronika, and P. Negeri Balikpapan, "Terakreditasi SINTA Peringkat 2 Pengaruh Variabel Kualitas Sistem Informasi Terhadap Kepuasan Pengguna Sistem Informasi Model EUCS," Masa Berlaku Mulai, vol. 1, no. 3, pp. 23-28, 2017.

[8] W. J. Doll and G. Torkzadeh, "The Measurement of End-User Computing Satisfaction EndUser Satisfaction The Measurement of End-User Computing Satisfaction Professor of MIS and Strategic Management The University of Toledo Gholamreza Torkzadeh Assistant Professor of Information Systems," Source MIS Q., vol. 1213512, no. 2, pp. 259-274, 1988.

[9] A. Saputra and D. Kurniadi, "Analisis Kepuasan Pengguna Sistem Informasi E-Campus Di lain Bukittinggi Menggunakan Metode Eucs," J. Vokasional Tek. Elektron. dan Inform., vol. 7, no. 3, pp. 58-66, 2019.

[10] W. Widiati, "Pengukuran Tingkat Kepuasan Mahasiswa dalam Penggunaan Sistem Informasi Akademik Menggunakan Pieces Framework (Studi Kasus: STMIK Nusa Mandiri Kampus Depok)," Paradigma, vol. XVIII, no. 2, pp. 81-88, 2016.

[11] R. S. Dewi, R. R. Marchada, and A. Rifai, "Analisa Pieces Penerapan Digital Monitoring Informasi Penyewaan Ruko Pasar 8 Pada Pt . Alam Sutera Realty, Tbk," Semin. Nas. Teknol. Inf. dan Komun. 2016 (SENTIKA 2016), vol. 2016, no. Sentika, pp. 18-19, 2016.

[12] A. Supriyatna, V. Maria, P. Studi, and M. Informatika, "khazanah informatika Analisis Tingkat Kepuasan Pengguna dan Tingkat Kepentingan Penerapan Sistem Informasi DJP Online dengan Kerangka PIECES," vol. 3, no. 2, pp. 88-94, 2017.

[13] P. L. Lokapitasari Belluano, I. Indrawati, H. Harlinda, F. A. . Tuasamu, and D. Lantara, "Analisis Tingkat Kepuasan Pengguna Sistem Informasi Perpustakaan Menggunakan Pieces Framework," Ilk. J. Ilm., vol. 11, no. 2, pp. 118-128, 2019, doi: 10.33096/ilkom.v11i2.398.118-128.

[14] A. Supriyatna, "Perpustakaan Dengan Menggunakan Pieces Framework," Pilar Nusa Mandiri, vol. Xl, no. 1, pp. 43-52, 2015. 